\title{
C. DIPHTHERIAE \\ II. SPECIFIC CHARACTERISTICS OF THE GROWTH GURVE OF C. DIPHTHERIAE
}

\author{
SHOKI NISHIDA \\ Microbiological Department, Faculty of Medicine, \\ Kanazawa University, Kanazawa, Japan
}

(Received: September 10th, 1954)

In a previous publication evidence was presented for the conclusion that biochemical activity of $C$. diphtheriae during the growth phase should be differenciated from those of other bacilli(1). It seems to be rather contradictorious to say that chemical activities of this organism fall to the minimum lebel during its growth phase. This paper develops further the experimental and theoretical aspects of the above facts by reporting quantitative deta relative to the viable counts of the bacilli at each stage of the growth and by checking morphological findings at the same time by light and electron microscopes.

Earlier study by Eisler(2) reported that the greater part of the pellicle consists of dead cells of $C$. diphtheriae. This was an excellent opinion but it is a pity that he did not show his experimental method and deta, because enumeration of the viable units of the suspension is considerablly controversial owing to the clumping characteristics of the organism. Author tried to overcome the difficuties by following technique.

\section{Materials AND Methods}

C. diphtheriae P.W. No. 8 (Tront strain) was used. Cells were grown on Popes medium. Each flask of $200 \mathrm{ml}$. of capacity contained $25 \mathrm{ml}$. of medium. The incubation temperature was $35^{\circ} \mathrm{C}$. Each two flasks were sampled at 24, $48,72,97$, and 146 hour intervals. The bacilli were then centrifuged and the supernatant decanted out. Each precipitate was sufficiently grounded with round bottom of sterilized test tube till it became to paste. Small volumes of saline were repeatedly added and the solution was made to the volume of $4 \mathrm{ml}$. $2 \mathrm{ml}$ of this preparation was diluted to $20 \mathrm{ml}$. with saline in the flask of $200 \mathrm{ml}$. capacity and shaken for $30 \mathrm{~min}$. Turbidity of each preparation was determined and made to a given optical density. These original solutions of $24,48,72,97$, and 146 hour cultures were diluted to $10^{-6}$ and $10^{-8}$ with salíne. $0.01 \mathrm{ml}$. of $10^{-6}$ and $10^{-8}$ dilutions were put on the blood plate agar media enriched with yeast extract and then spread on the surfaces of the media with glass spatulas. The agar plates were used in triplicate to each dilutions. (Blood was useful not only for the enrichment of the media but for the enumeration of the viable counts 
on the surfaces owing to the clear contrast against the red background. To make clear contrast phenol red was also available but viable counts were 20 to $30 \%$ less than those in blood plate agar media.)

In second and third experiments tween 80 was used to acquire complete homogeneous suspension of this organism. To each precipitate in the centrifuge tube tween 80 was mixed up into paste by the procedure described above.

The dates on which the bacilli were harvested and the degree of dilutions was a little different from those in the first experiment.

\section{RESULTS}

Viable counts in $10^{-6}$ and $10^{-8}$ dilutions of the original solutions are shown in Table 1. As can be seen from the results presented the number of the bacilli is not diluted in correspondence to the dilutions of the suspension. The younger the culture is, the more markedly the disagreement can be seen. This is owing to the fact that the suspension of the younger cultures still consist of a number of clumps of alive bacilli and dissociate more and more as the dilutions go on. This suggests that real number of individulal cell in the suspension never can be enumerated from the results in Table 1. Therefore reciprocal ratios in a given

Table 1. Viable counts of C.diphtheriae at each stage of culture

\begin{tabular}{|c|c|c|}
\hline $\begin{array}{l}\text { Dilutions } \\
\text { Incubation }\end{array}$ & $10^{-6}$ & $10^{-8}$ \\
\hline 24 (hours) & $\begin{array}{r}1332 \\
1121 \\
951 \\
\end{array}$ & $\begin{array}{l}493 \\
320 \\
290\end{array}$ \\
\hline $48(,)$, & $\begin{array}{l}445 \\
425\end{array}$ & $\begin{array}{l}92 \\
76 \\
67 \\
\end{array}$ \\
\hline${ }^{72}(, \quad)$ & $\begin{array}{l}225 \\
217\end{array}$ & $\begin{array}{l}35 \\
32 \\
\end{array}$ \\
\hline 97 (, , ) & $\begin{array}{l}28 \\
30 \\
22\end{array}$ & $\begin{array}{l}3 \\
0 \\
0\end{array}$ \\
\hline $146()$, & $\begin{array}{r}1 \\
10 \\
1\end{array}$ & $\begin{array}{l}0 \\
0 \\
0\end{array}$ \\
\hline
\end{tabular}

concentration are compared. If it is assumed for convenience that the bacilli at 24th hour culture are alive $100 \%$, the viable cell curve can be plotted from the reciprocal ratios and the growth shown in Fig. 1 . The procedure is as followis. Enumeration was made on the results in $10^{-8}$ dilution

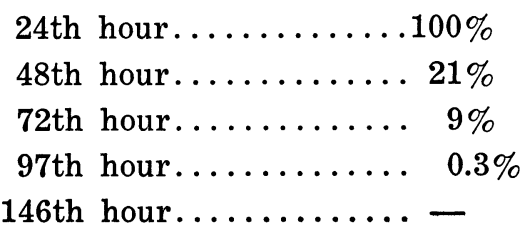


Therefore, viable cells can be enumerated as follows.

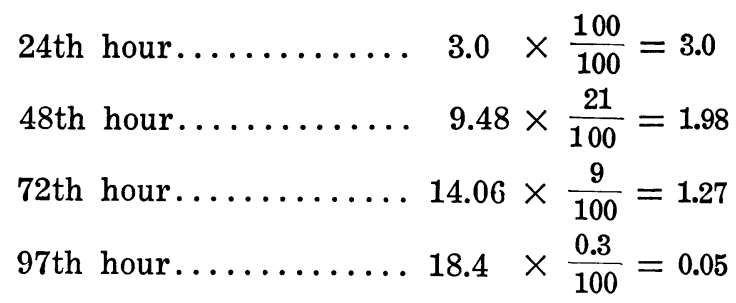

They are demonstrated with the unit of $\mathrm{mg}$. in Fig. 1

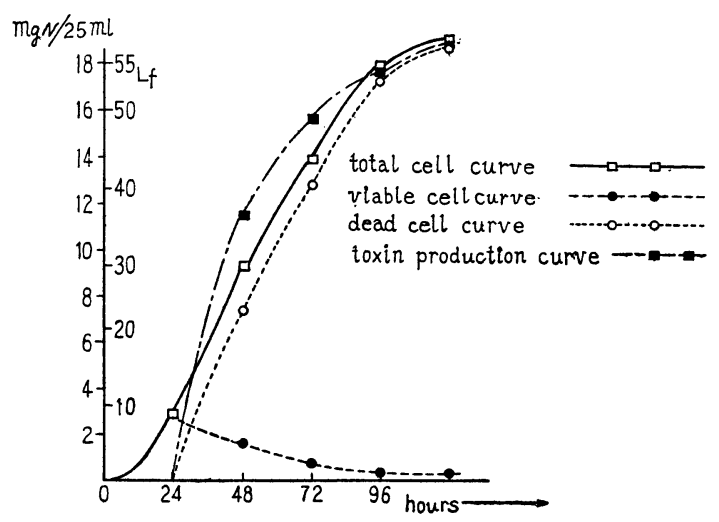

Fig. 1. Various curves in the course of the growth of C. diphtheriae

The difference between the figure in total curve and the figure in viable cell curve at each stage of culture corresponds to the figure in dead cell curve. As, needless to say, the figure of $100 \%$ at 24th hour culture is grounded on an assumption that all the bacilli are alive in this stage and, in fact, the number of viable cells are supposed to be less, the real curve of the viable cells possibly sinks downwards and that of dead cells becomes nearer to the total cell curve shown in Fig. 1. Moreover, the trend will be more strengthened if the clumping nature of the younger bacilli is taken into consideration. It is clear from these results that the organism really participating in multiplication is very few. In other words, the growth curve of $C$. diphtheriae may well be said as accumulation curve of dead cells, as far as the conditions used new are concerned. These findings coincide with the facts of the singular activity described in the preceding paper.

The same experiments except using of tween 80 were done. From the data presented in Table 2 the dissociation of clumps of the bacilli seems to go fairly well. From this Table the viable cell and dead cell curves are plotted in Fig. 2. It must be noticed from Fig. 1 and Fig. 2 that the toxin production 
Table 2. Viable counts of C.diphtheriae at each stagge of culture

\begin{tabular}{|c|c|c|c|c|}
\hline hours & $10^{-3}$ & $10^{-5}$ & $10-7$ & $10^{-9}$ \\
\hline 24 & innumerable & $\begin{array}{l}575 \\
476\end{array}$ & $\begin{array}{l}3 \\
0 \\
0\end{array}$ & $\begin{array}{l}0 \\
0 \\
0\end{array}$ \\
\hline 48 & innumerable & $\begin{array}{l}16 \\
11\end{array}$ & $\begin{array}{l}0 \\
0 \\
0\end{array}$ & $\begin{array}{l}0 \\
0 \\
0\end{array}$ \\
\hline 72 & innumerable & $\begin{array}{l}13 \\
25 \\
40\end{array}$ & $\begin{array}{l}0 \\
0 \\
0\end{array}$ & $\begin{array}{l}0 \\
0 \\
0\end{array}$ \\
\hline
\end{tabular}

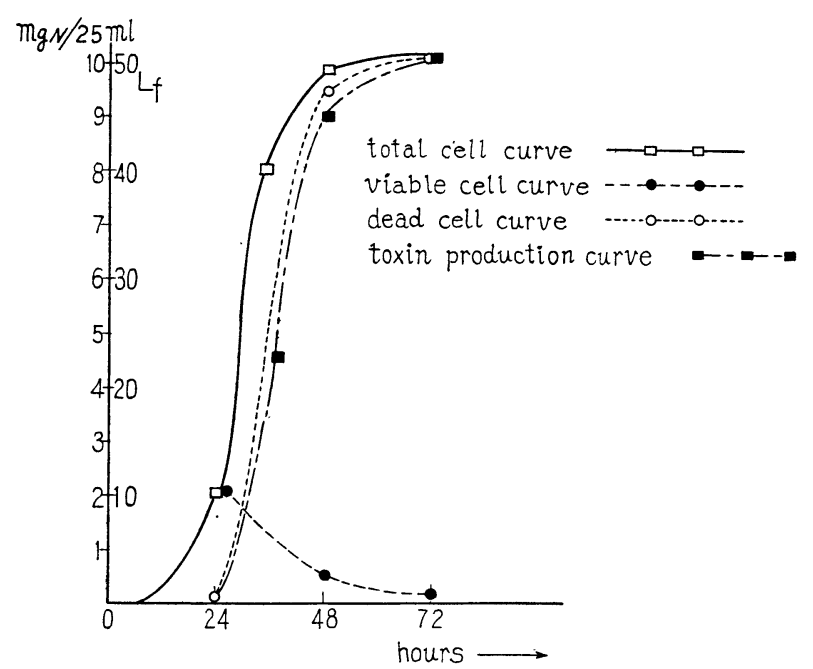

Fig. 2. Various curves in the course of the growth of C. diphtheriae

curve is not parallel to the viable cell curve but almost parallel to the dead cell curve. Thus it was proved to be erroneous to conclude the secretion of the exotoxin from the actively growing cells of $C$. diphtheriae only by seeing the relation between the toxin production and the growth. Fig. 3 shows the relation between the total cell curve and the viable cell curve in iron rich medium $(2 \gamma \mathrm{Fe} / \mathrm{ml}$.) The same findings could be seen except no toxicity in culture filtrate. It is clear from this result that existence or non existenxe of iron ion in the medium has no influence on the viability of the bacilli.

Next experiment was undertaken to see if morphological changes could be observed in the course of the biochemical inactivation and the accumulation of the dead cells. At each stage of culture in Fig. 1 the bacilli were reaped and observed by light and electron microscopes. At first the findings by light microscope were described. In 24 hours most of the bacilli showed strong and even stainability of their cytoplasms. (Lf 2 in culture filtrate). In the course of following 24 hours, however, rapidly increased the bacilli which showed metachromatic bodies in the cytoplasms. At 48 th hour culture a majority of the bacilli was seen to be changed into the form containing the bodies. It must be noticed 


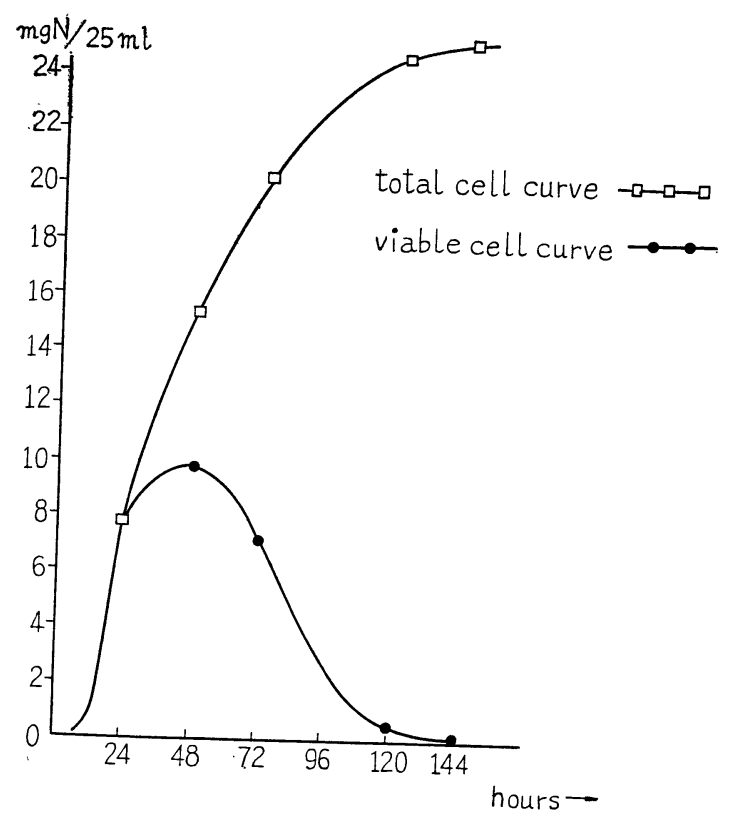

Fig. 3. Total cell curve and viable cell curve of $C$. diphtheriae iron rich medium $(50 \mathrm{r} / 25 \mathrm{ml})$

here that the commencement of toxin production and the biochemical inactivation was always in accordance with that of the appearance of the metachromatic bodies in each cell. ( $\mathrm{Lf}=35$ in culture filtrate). At 72th and 97th hours the bacilli having the metachromatic bodies increased overwhelmingly. (Lf. 55 at 97th hour in culture filtrate). Hereafter, general stainability was lost day by day.

As for Gram's staining the stainability was invariable through the experiment.

These changes were also observed with electron microscope. As can be seen in Fig. 4 cytoplasms of the bacilli at the 20th hour culture showed strong and even electron scattering power. The boundaries of the bacilli against the background could be seen very distinct. The toxin yield in culture filtrate was 0 Lf. At 48th hour culture a majority of the bacilli transformed into the cells having high transparency to electron, though the growth rate was the same as that of preceding hours. (Fig. 5) More than half of these bacilli at this stage showed dambel shape of dense bodies which was supposed to be the metachromatic body.

Coinciding with the transformation the toxin never fail to be excreed into the medium as far as the medium was iron-defficient. Electron micrograph of the bacilli reaped at $97 \mathrm{th}$ hour, the period of decelerating growth rate, showed quite unordinary forms which suggested the unordinary biochemical inactivation and the few viability described before. (Fig. 6) Low refringence of their cytoplasms showed markedly uneven transparency owing to the dense bodies 
contained in each cell. Considered from the viable counts and the biochemical inactivation the loss of dense mass from the cytoplasms was thought to be related to the degradation or elution of the cytoplasmic constituents.

In shadowed preparation also the bacilli at 20th hour were full of cytoplasmic content, (Fig. 7), while the bacilli at 97 th hour, a time in the period of decelerating growth rate, showed remarkablly shrinkage of the cytoplasms, probably owing to the elution of content. (Fig. 8) It is clearly seen from morphological point also that the period of decelerating growth rate of $C$. diphtheriae should be differenciated from those of other bacilli. It has been believed up to date that a number of materials, such as cytoplasmic protein ${ }^{(3)}$, $\operatorname{proteinase}^{(4)}$, porphyrin ${ }^{(5)}$, flavin (6), toxin(7) (8) (9), and etc. ware secreted in their actively growing phase, though it has long been the undissolved problem to the students of $C$. diphtheriae why the bacilli secrets such a variety of important materials in growth phase. It was described in this paper that the postulation was misunderstanding owing to the overlooking of the special characteristics of the growth.

\section{Discussion}

It must be noticed that the biochemical inactivation does not always occur in accordance with the accumulation of the dead cells, because there are many cases in which bacilli are alive but have lost their enzymic activities. Here must be noticed what a percent of the total cells is the physiologically young cells really participating in proliferation. As far as author's circumstances are concerned, it seems that the inactivated cells promptly go to death or to the state in which the bacilli cannot grow on the blood plate agar media. This is a reason for the agreement between the inactivation curves of enzymes and the viability, in a given concentration of suspension. Reinvestigating author's experiment $\mathrm{T}$. Yamanaka(10) recently described the disagreement between them in his case in which P.L.O. medium(11) was used, though he also acknowledged the concurrent fall of almost all the constitutive enzyme activities in growth phase like the experiment by author. With use of shaking culture in the pope's medium this disagreement was demonstrated by author, too, as it will be reported in next paper. Thus it is probably dangerous to persist on the findings of the viable counts whether they may be abundant or few. What is important in this case is not the number of viable cells but the number of physiologically young cells really participating in multiplication. It was fortunate for author, trying to clarify the characteristics of the growth curve of $C$. diphtheriae that inactivated but alive cells of $C$. diphtheriae were few in author's medium. Being considered from its singular death rate this organism does not seem to proliferate as ordinary bacilli multiply by binary fission. 
In $M$. tuberculosis avium, biologially akin to $C$. diphtheriae author could demonstrate the same relation between the enzymic activities and the growth phase, though the viable cell curve was closely parallel to the total cell curve(12). This common nature in biochemical activities is interesting to author because two groups of the bacilli have a biologically special mode of proliferation, such as branching or cord formation like fungi. There are many excellent works about the growth mode of $M$. tuberculosis and, on the contrary, few works about that of $C$. diphtheriae. Ueda(13) described in his studies on the growth mode of $M$. tuberculosis that only the cell at the top of the cord participates in proliferation and the more distant the cells in the cord are situated from the growing cell, the more inactive they become. As regard to two groups of organisms which proliferate accompanying overwhelmingly numerous inactivated cells, they must be reinvestigated from this viewpoints. It must be careful, at any rate, for $C$. diphtheriae as well as $M$. tuberculosis that physiologically young cells cannot be so easily obtained as those of $C l$. tetani or S. dysenteriae. This is one of principal reasons why the cells of $\mathrm{Cl}$. tetani or S. dysenteriae in early stage of culture have potent toxin within the cells and, on the contrary, the cells of $C$. diphtheriae in early stage of culture have no toxin within their cells. Though, needless to say, physiologically young cells can be obtained in very early stage of culture, the bacilli collected are too few and in this state are so easily influenced by contaminated iron ion that no toxin can be produced within the cells. Consequently the demonstration of the toxin within the cells seems to be impossible as far as static culture, in which the growth curve is closely parallel to the dead cell curve or to degradated cell curve, is used. In next paper it will be reported that physiologically young cells obtained by shaking culture contain the highest toxin ever reported.

\section{CONCLUSION}

1. The accumulation curve of dead cells in the course of the growth of C. diphtheriae is very closely parallel to the total cell curve of this organism.

2. The toxin production is completely parallel to the growth curve, which, in fact, may well be said the accumulation curve of dead cells.

3. In accordance with the biochemical inactivation and the toxin production the metachromatic bodies appear within the cells. As the inactivation and the toxin production went on, these bacilli overwhelmingly increased. Electron microscopic observation showed remarkable transition of electron density in growth phase.

4. It was concluded from these results that the physiologically young cells of $C$. diphtheriae can not be so easily obtained as those of $\mathrm{Cl}$. tetani or of $S$. dysenteriae as far as static culture is used. 


\section{ACKNOWLEDGEMENT}

Grateful acknowledgement is made to Prof. T. Tani for helpful encouragement and revision.

\section{REFERENCES}

1) Nishida, S.: C. diphtheriae 1. The relation between the toxin production and the growth curve of $C$. diphtheriae. Jap. J. Med. Sci. \& Biol. 7, 445 452, 1954.

2) Eisler, M.: Zur genese und charakteristik der Bakteriengift. Z. Immunt. Forsch., $56,209 \sim 233,1928$.

3) Brandwijk, A. G., Tasman, A., and Ramshorst, J. D.: The relation between toxin production and protein synthesis by $C$. diphtheriae. J. Infect. Dis., 87, 99 102, 1950.

4) Pope, C. G., Stevence, M. F., Gaspary, E. A., and Fenton, E. L.: Some new observation on diphtheria toxin and antitoxin. Brit. J. Exper. Path., 32, 246 〜 258, 1951.

5) Coulter, C. and Stone, F.: The occurence of porphyrins in cultures of C. diphtheiae. J. Gen. Physiol.,14, 583 591, 1931.

6) Mitsuhashi, S., Murakami, M. and Yagi, K.: On the production of the toxin by C. diphtheriae III. The condition of the formation of flavin compounds. Jap. J. Exper. Med., 22, 1 7, 1952.

7) Pope, C. G., and Healey, M.: Surface growing and toxin production of $C$. diphtheriae. Brit. J. Exper. Path., 14, 87 92, 1933.

8) Brandwijk, J. K., Tasman, A., and Remshorst, J. D.: The relation between toxin production and protein synthesis by $C$. diphtheriae. J. Infect. Dis., 87, 99. 102, 1950.

9) Morton, H. E. and Gonzalez, L. M.: On the site of formation of diphtheria toxin. J. Immunol., 45, 63 69, 1942.

10) Yamanaka, T.: Studies on the diphtheria toxin production. At the 27th Meeting of Japanese Bacreiological Society. 1954.

11) Ozaki, Y.: Recherches sur les lormogénesés du Bacille diphtherique dans la toxine production medium P. L. O. J. Osaka Medical University for Woman, $6,10 \sim 14$, 1953. (in Japanese)

12) Nishida, S., and Kawakami, K.: Studies on M. tuberculosis. I. Chemical activities and growth curve of M. tuberculosis avium. At the 27th Meeting of Japanese Bacteriological Society. 1954.

13) Ueda, S.: Studies on $M$. tuberculosis I. The morphology and the growth mode., Nankodo, Tokyo, Japan. (in Japanese), 1951. 


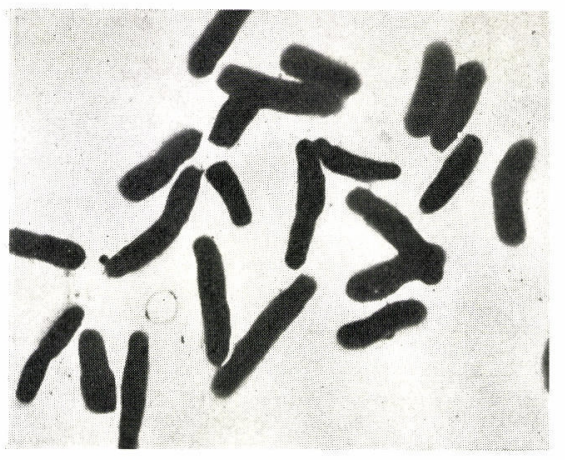

Fig. 4. Cells of C. diphtheriae at 20 th hour in experiment 1. (Fig. 1)

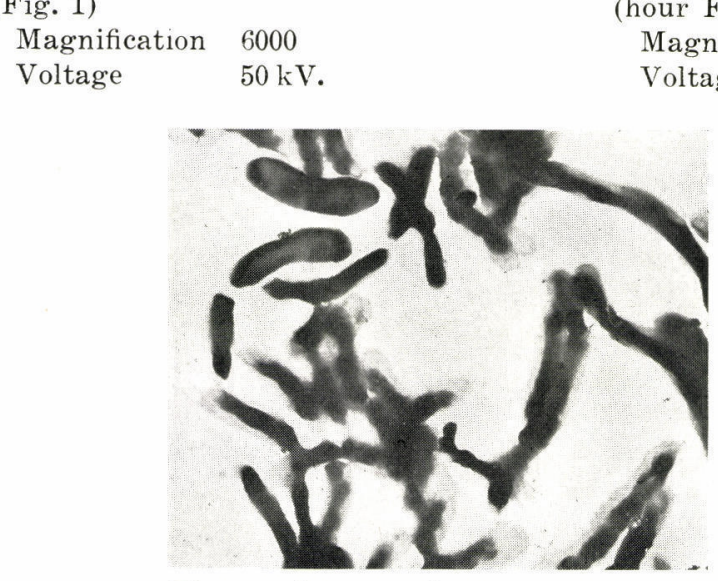

Fig. 6. Cells of $C$. diphtheriae at $g^{\prime}$ th hour in experiment 1 . (Fig. 1)
Magrification
Voltage

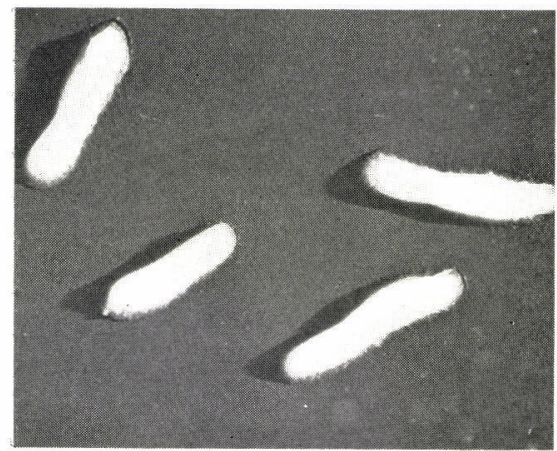

(Shadowed)

Fig. 7. Cultural condition is the same as that in Fig. 4. Magnification 8000

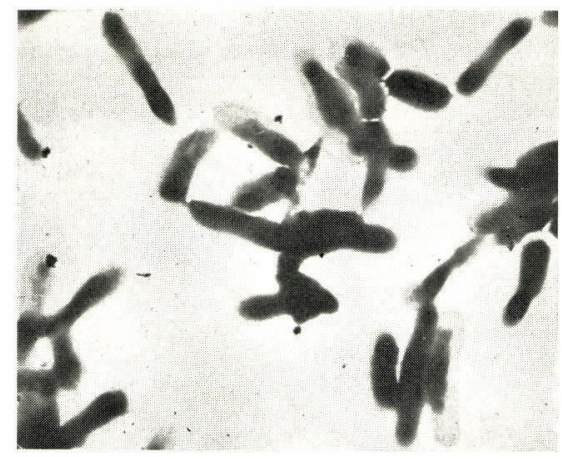

Fig. 5. Cells of C. diphtheriae at 48th hour in experiment 1. hour Fig. 1)

Magnification 6000 oltage $\quad 50 \mathrm{kV}$. 